\title{
Postphenomenological Method and Technological Things Themselves
}

\author{
Martin Ritter ${ }^{1,2}$ (D)
}

Accepted: 12 July 2021 / Published online: 9 August 2021

(C) The Author(s) 2021

\begin{abstract}
We live in a world where it is impossible to exist without, and beyond, technologies. Despite this omnipresence, we tend to overlook their influence on us. The vigorously developing approach of postphenomenology, combining insights from phenomenology and pragmatism, focuses on the so-called technological mediation, i.e., on how technologies as mediators of human-world relations influence the appearing of both the world and the human beings in it. My analysis aims at demonstrating both the methodological weaknesses and open possibilities of postphenomenology. After summarizing its essentials, I will scrutinize, first, its ability to turn to the technological things themselves and, second, the so-called empirical turn as realized by postphenomenology. By assessing its conceptual framework from the phenomenological perspective, I hope to demonstrate that postphenomenology needs philosophical clarification and strengthening. In short, it needs a more phenomenological, and less pragmatic, approach to technology in its influence on human experience.
\end{abstract}

Keywords Empirical Turn · Philosophy of Technology · Postphenomenology • Pragmatism · Technological Mediation

\section{Introduction}

Is postphenomenology phenomenological (enough)? By seeking to answer this seemingly simple yet, in fact, very broad question, I aim to assess whether postphenomenology is a more concrete kind of phenomenology, or, rather, a distorted phenomenology, or perhaps something other than phenomenology. Let me state right away that my analysis will question the phenomenological character of postphenomenology. But the purpose of this investigation is not to reject postphenomenology for

\section{Martin Ritter}

ritter@flu.cas.cz

1 Institute of Philosophy, The Czech Academy of Sciences, Jilská 1, 11000 Prague 1, Czechia

2 Department of Philosophy, University of Vienna, Universitätsstraße 7, 1010 Vienna, Austria 
being insufficiently phenomenological. I will critically analyse the method of postphenomenology not only to highlight its glitches but also to point out its still open and underdeveloped possibilities — as they become visible from the phenomenological perspective.

Postphenomenology promises to elucidate how profoundly technologies condition human experience. Concentrating on human interrelations and interactions with concrete artefacts, it seeks to avoid speculations and bringing preconceived conceptual schemata into our reflections on technology. In accord with Husserl's watchword of phenomenology, the postphenomenological philosophy of technology wants to stay close to things themselves, i.e., particular technologies. In this sense, it aspires to be a philosophy from technology (Verbeek 2016: 190). Critics of postphenomenology usually complain about its alleged insensitivity to broader contexts, for example, the social or political contexts, of human being with technology. In this paper, I take a different road. Instead of asking whether postphenomenology can do justice to these contexts, I focus on its ability to turn to the technologies themselves. I intend to demonstrate that postphenomenology, insofar as it tends to identify the technicity of things with their pragmatic function, is in danger of becoming unable to fully realize and appreciate their own power. I critically analyse the empirical character of postphenomenology as well to indicate that postphenomenology needs to broaden its research field when looking for the empirical origins of technological mediation.

I begin, in Part 1, by articulating how the eminent proponents of postphenomenology conceptualize the essentials of their approach(es). In Part 2, I scrutinize how postphenomenology proceeds when turning to the things themselves. In Part 3, I critically analyse the so-called empirical turn as realized by postphenomenology. The main critical point of my analysis can be articulated quite simply: postphenomenology risks not identifying technology, and hence not elucidating technological mediation, beyond what is "naturally" understood as technology. The main purpose of my analysis is to indicate that this limitation is undesirable, perhaps inadvertent, and certainly unnecessary.

\section{Postphenomenology}

It seems not only appropriate but even imperative to begin analysing the postphenomenological conceptual framework by reviewing the ideas of its founder and godfather Don Ihde. Conveniently, we can use here the first of his four Peking University Lectures, delivered in 2006 and published in 2009 under the title Postphenomenology and Technoscience. In the lecture called "What is Postphenomenology," Ihde characterizes postphenomenology in three steps. First, in the approach of postphenomenology, phenomenology becomes complemented or enriched by pragmatism. According to Ihde, if Husserl had used the resources available from pragmatism, resources able to deconstruct the "early modern epistemology" he still relied on, it "would have yielded a nonsubjectivist and interrelational phenomenology" (Ihde 2009: 11), i.e., postphenomenology. Second, and conversely, in postphenomenology, pragmatism becomes enhanced by phenomenology. "Husserl's phenomenology 
contained methods that, had these been adapted in pragmatism, would have enriched its analysis" (Ihde 2009: 11). More concretely, pragmatism brings "its recognition that 'consciousness' is an abstraction, that experience in its deeper and broader sense entails its embeddedness in both the physical or material world and its cultural-social dimensions," while phenomenology provides "its more rigorous style of analysis that develops variational theory, recognizes the role of embodiment, and situates this in a lifeworld particular to different epochs and locations" (Ihde 2009: 19). The third step identified by Ihde is "the step away from generalizations about technology überhaupt and a step into the examination of technologies in their particularities" (Ihde 2009: 22). Specifically, postphenomenology focuses on technologies as interrelating human beings and the world. Based on identifying this mediating (inter)relationality with the phenomenological concept of intentionality, or the fact that consciousness is always consciousness of something, postphenomenology claims that "technologies can be the means by which 'consciousness itself' is mediated. Technologies may occupy the 'of' and not just be some object domain" (Ihde 2009: 23). This mediating role of technologies should be analyzed empirically, by undertaking "concrete-empirical-studies of technologies in the plural" (Ihde 2009: 23).

After this brief sketch of (a few of) Ihde's ideas, allow me to proceed to his most influential followers. In Postphenomenological Investigations, published in 2015, its editors Robert Rosenberger and Peter-Paul Verbeek offer "A Field Guide to Postphenomenology" in which they identify typical features of postphenomenology as a form of empirical philosophy. Although postphenomenology, according to Verbeek and Rosenberger, does not follow a strict methodology, its modus operandi can be "defined" by four elements. First, postphenomenology focuses "on understanding the roles that technologies play in the relations between humans and world" (Rosenberger and Verbeek 2015: 31). Second, "postphenomenological studies always include empirical work as a basis for philosophical reflection" (Rosenberger and Verbeek 2015: 31). This reflection, third, seeks to elucidate "how, in the relations that arise around a technology, a specific 'world' is constituted, as well as a specific 'subject'" (Rosenberger and Verbeek 2015: 31). And, based on the aforementioned, "postphenomenological studies typically make a conceptual analysis of the implications of technologies for one or more specific dimensions of human-world relations-which can be epistemological, political, aesthetic, ethical, metaphysical, et cetera" (Rosenberger and Verbeek 2015: 31). Postphenomenology does not focus on concrete technologies to merely describe how they, or more precisely "the relations that arise around" them, constitute specific objectivities (worlds) and subjectivities (human persons). Rather, this description aims at making it possible to elucidate, and evaluate, the practical consequences of this twofold constitution. And this is also why, and where, postphenomenology has close ties to design: according to postphenomenology, we should seek not only to understand technologies in their constitutive "power" but to design their morality based on our understanding of them (see Verbeek 2011).

The last publication to be included in this overview is a collective volume focusing on postphenomenological methodology. In the "Introduction" to Postphenomenological Methodologies, published in 2018, its editors Jesper Aagaard, Jan Kyrre 
Berg Friis, Jessica Sorenson, Oliver Tafdrup, and Cathrine Hasse strive to identify "a few watersheds in the transition from 'classical' to 'post' phenomenology that specifically focuses [sic] on methodology" (Aagaard et al. 2018: xii). They begin, quite naturally, with a postphenomenological adoption of Husserl's idea of intentionality: directedness (of consciousness) toward the world. This intentionality is, as emphasized especially by Merleau-Ponty, embodied. And when bodily experiencing through our intentions, we form habits while these habits (in)form our experiencing of the world. Following phenomenology, postphenomenology employs the method of eidetic variation. Yet, it adds to it a crucial twist: "when employing variational analysis ..., what is revealed is multistability rather than stable essences" (Aagaard et al. 2018: xiii). Indeed, as a nonfoundational and anti-essentialist form of philosophy, postphenomenology does not look for invariant essences but rather for different possibilities of using technological artefacts (see Rosenberger 2017). More concretely, postphenomenology focuses on technology in its ability to shape intentionality and intentional action: "Technologies not only transform perceptions, ... they also invite (Verbeek 2005) and facilitate (Rosenberger 2014) certain actions, while inhibiting and foreclosing others. Accordingly, they do not afford action possibilities to preexisting subjects with fixed goals, but subtly guide, nudge, and steer our intentionality (Verbeek 2005)" (Aagaard et al. 2018: xvi). In other words, technologies, as the media of intentionality, shape - "guide, nudge, and steer" - intentionality itself, and thus coshape subjectivity and objectivity. Like all the previously mentioned postphenomenologists, the editors of Postphenomenological Methodologies? emphasize the empirical turn as well: "postphenomenology inverts or at least symmetrizes Heidegger's ontological difference, with which he famously argued that Being cannot be explained through entities: what things do equally cannot be explained with recourse to the abstract being of Technology" (Aagaard et al. 2018: xvii).

Let me summarize, based on the aforesaid, how postphenomenology understands itself. Put succinctly, postphenomenology is, to use Ihde's words, a "hybrid phenomenology" (Ihde 2009: 23) which seeks to capture, based on empirical research, how technologies mediate humans and (their) world. It takes on the concepts like intentionality or embodiment from phenomenology. Yet, it enriches phenomenology by empirically analysing the various ways technology shapes intentionality, and, by extension, subjectivity and objectivity. Hence, one might conclude that postphenomenology is a more concrete form of phenomenology; namely, one concretized by its empirical focus on concrete technologies. But is this true?

\section{Things Themselves}

I would like to begin my critical investigation by turning the attention to the exchange of viewpoints between Peter-Paul Verbeek, a prominent postphenomenologist, and Pieter Lemmens. Verbeek claims that Lemmens' approach is "not empirically informed" and fails to investigate "actual technologies" (Verbeek 2017: 301f.); instead, it applies "pre-given philosophical frameworks" "from outside" (Verbeek 2017: 303). As a remedy, Verbeek suggests realism: "A realism in the 
phenomenological sense of going back "to the things themselves"' (Verbeek 2017: 304). Lemmens, in turn, describes Verbeek's standpoint as follows: it should be "a more hermeneutic approach oriented towards 'the things themselves,' here understood not 'in the phenomenological sense' (as Verbeek nonetheless claims) but empirically, in the way STS approaches technology" (Lemmens 2017: 307). As one can see, Lemmens questions Verbeek's claim that postphenomenology turns to the things themselves phenomenologically. He adds: "[S]urely neither Husserl nor Heidegger ever thought of 'die Sachen selbst' as concrete objects; these were precisely 'bracketed' in order to attain the proper phenomenological Sach-dimension: the acts of transcendental consciousness (like intentionality) for Husserl, modes of being for Heidegger" (Lemmens 2017: 307).

I mention this discussion because it nicely captures the problem(s) I want to focus on in this paper. To be able to analyse things as they are given in experience, phenomenology does not approach them in an empirical way but considers it necessary to realize specific methodical steps which make things accessible. Verbeek does not see such steps as necessary, and hence his approach cannot be called, Lemmens maintains, "realistic" in the phenomenological sense. In fact, Verbeek declares realism to emphasize that philosophy of technology should stay in touch with empirically given technologies rather than working with general and abstract concepts, or transcendental conditions. In the following, I will not discuss whether "analysing technologies in complete abstraction from the politico-economic conjuncture ... is also pretty unrealistic" (Lemmens 2017: 309). Instead, I will scrutinize whether Verbeek's realism is able to do justice to technological things themselves in their mediating subjectivity and objectivity. Specifically, I seek to demonstrate that it might not be the case so long as technologies are understood and approached pragmatically, as implied by Ihde's definition of postphenomenology: "phenomenology + pragmatism = postphenomenology" (Ihde 2012: 128).

Verbeek tries to depict a sort of natural evolution from phenomenology to postphenomenology. According to him, "phenomenology presented itself ... wrongly ... as a philosophical method that sought to describe "reality itself" (Verbeek 2005: 104). This self-presentation errs because there is no possibility to directly see things or to describe them themselves. As Verbeek puts it in Moralizing Technology, it is "more in accordance with the actual history of phenomenology to see phenomenology as a philosophical movement that seeks to analyze the relations between human beings and their world rather than as a method for describing reality" (Verbeek 2011: 15). And already in What Things Do: phenomenology should be understood "as a philosophical movement whose principal task is to analyze the relation between human beings and their world rather than as a method of describing reality" (Verbeek 2005: 108). Postphenomenology as a nonsubjectivist and interrelational phenomenology then focuses on what mediates the subject-object relation. And since technology is, in the age of technoscience, one of the mediators, if not the most powerful one of all, postphenomenology analyses technologies as codetermining or coshaping subjects and objects. "When technologies mediate the intentional relation between humans and world, this always means from a phenomenological perspective that they codetermine how subjectivity and objectivity are constituted" (Verbeek 2005: 116). 
Verbeek explicitly mentions the watchword of phenomenology, "to the things themselves!," claiming that he heeds Husserl's call literally (Verbeek 2005: 12) and requires a turn to technological artefacts or simply a "thingly turn" (Verbeek 2005: 3 ). Verbeek thrives on criticizing the Western world and its philosophy for underrating things in their materiality: "The Western world does not attach as much value to things as one might expect" (Verbeek 2005: vii) and especially "philosophy has failed to recognize the significance of things and their materiality" (Verbeek 2005: 2). To resist this undervaluation, his own "philosophy of materiality," seeking not to reduce things to "non-thingly elements" (see Verbeek 2005: 2), wants to develop a "new way of thinking in particular with respect to technical or technological objects, which are the most distinctive class of objects in contemporary technological culture" (Verbeek 2005: 3).

At first glance, Verbeek's position might resemble that of Graham Harman's object-oriented philosophy (see, e.g., Harman 2002 or 2017): we should focus, or at least attempt to try to, on objects in their autonomous existence. But this is not the case. In contrast to the object-oriented approach, postphenomenology does not claim that objects, namely technologies, exist independently of their relations to humans. To the contrary, technological things are defined in postphenomenology by their being part of human relations. As Verbeek puts it: "Artifacts can only be understood in terms of the relation that human beings have to them," and, more concretely, "technologies cannot be separated from their use contexts" (Verbeek 2005: 117). Accordingly, there is "one pitfall that needs to be avoided in this analysis of the ability of artifacts to coshape the relation between human beings and world: this ability must not be conceived as an intrinsic property of the artifact itself" (Verbeek 2005: 117). But, if this ability is not intrinsic to the thing, and hence does not follow from the thing itself, can we reasonably speak here of any turn to the things themselves? Postphenomenologists rightly underline that technologies are not mere materialities: the thing is technical not due to its materiality alone. But what is the ability of the technological thing to mediate the intentional relation if not its intrinsic property? In the rest of this section, I seek to indicate that postphenomenologists risk not doing justice to the ability of technologies themselves to coshape the relation between human beings and the world insofar as they tend to reduce the technicity of the things to their pragmaticity, or their (meaning in) use.

Allow me to quote Verbeek (who quotes Ihde as well): "[T]echnologies always and only function in concrete, practical contexts and cannot be technologies apart from such contexts. In Ihde's words, 'Were technologies merely objects totally divorced from human praxis, they would be so much "junk" lying about. Once taken into praxis one can speak not of technologies "in themselves," but as the active relational pair, human-technology", (Verbeek 2005: 117). Of course, on one hand, it is fully reasonable to emphasize that technologies are technologies only insofar as they function in human practical contexts. Yet, on the other hand, if postphenomenology explicitly aims at elucidating the role of technological things, then it must focus not merely on the relational pair "human-technology" but rather on the respective technology itself as a part of this relational pair. In postphenomenology as currently practised, the mediating "power" of this part becomes reduced to what it does insofar as it is used by humans. But the mediating ability of the technological thing as 
a part of this pair is irreducible to what it does in its pragmatic function. As long as postphenomenology conceptualizes technology pragmatically, i.e., as a part of a human-technology relation dependent on human pragmatic relation to it, it risks not turning fully to the technological things themselves.

Postphenomenologists intend to analyse technological artefacts themselves as they shape intentionality with their own intentionalities. Accordingly, Ihde speaks of technologies as forming "intentionalities" (Ihde 1990: 141) and Verbeek of "the intentionality or trajectory of things" (Verbeek 2005: 115). Expanding on Ihde's famous distinguishing of four human-technology relations (Ihde 1990), namely embodied, hermeneutic, alterity, and background relations, Verbeek adds the concepts of "hybrid intentionality," where technology with its own intentionality contributes to creating "a new entity" (Verbeek 2008: 391), and of "composite intentionality," in which "humans are directed ... at the way in which a technology is directed at the world" (Verbeek 2008: 393). As one can see here, Verbeek surely conceives of technological things as having their own intentionalities. But I insist that postphenomenologists cannot have it both ways: they cannot build on technology's own intentionality and simultaneously hold that technology's own being is always already defined by its place in human praxis. We can either seek to fully realize what technological things can do even beyond our intentions or identify their technicity, in a pragmatic way, merely with what they do as parts of our practical contexts. Accepting the pragmatic definition of things, we risk missing something of (or in) them that mediates the intentional relation between humans and world. If postphenomenologists seek to fully appreciate technologies' own "intentionalities," they should not reduce the technicity of the thing to its meaningful functioning in human context.

To use an extreme example: Even the "“junk' lying about” (Ihde 1993: 34) mentioned above, i.e., a thing we do not (know how to) use, surely has its own materiality, and perhaps even intentionality. In the postphenomenological theoretical framework, this non-pragmatic materiality (its "own" materiality, so to speak) codetermines the very technicity of the thing only negatively: it allows for doing many "things" with this "junk," and hence to make many (practical) things from this one thing, but it does not allow everything; it limits the possibilities of how it can be used. Yet, what the thing in its technicity really is, or rather becomes, is positively determined by the context, and the context is constituted neither by the thing itself nor by other objects (other "junk") but by human praxis broadly conceived. If you allow me to formulate it in a provocative way, I would draw an analogy between how Husserl describes the constitution of a thing in consciousness and how postphenomenology conceives of a technological thing in its technicity. According to Husserl (1970), the thing is constituted thanks to the activity of consciousness which "animates" so-called hyletic data. Consciousness needs this data as material from which it—metaphorically speaking — "builds," i.e., constitutes the thing. This hyletic data is necessary, even indispensable. But still: it is consciousness which animates, or interprets, it. I suspect a similar structure is "at work" in postphenomenology when it conceptualizes the technological thing: in its own materiality, it is indispensable, yet it becomes what it is, i.e., a multistable technological thing, strictly by being "animated," i.e., used in human praxis. This is not to say that the thing can 
become/be whatever one imagines it to be. It is not the case not only because its materiality does not make everything possible. Just as importantly, the very meaning of the thing, or its meaning in our praxis, is not constituted by my wilful individual consciousness but rather trans-individually, and, from the perspective of an individual consciousness, un-consciously or unwittingly: in Husserl's phenomenology by transcendental intersubjectivity; in postphenomenology by a pragmatic community with its "culture". In both cases, however, the "autonomy" of the thing comes short.

Consequently, postphenomenology suffers from two interconnected problems. On one hand, when emphasizing the multistability of technological artefacts, it tends to approach technological things as malleable or pliant to what we do with them. Such an approach is in danger of becoming unable to fully realize and appreciate things' own agency. On the other hand, and even more importantly, by naturally assuming that technology is what we (a pragmatic community) see as technology, postphenomenology in its intention to do philosophy from technology may end by doing philosophy from what we consider to be, or constitute as, technology. Technologies as the things to be analyzed by postphenomenology must not be reduced to pragmatically conceived (technological) things. Postphenomenology should not focus on the pragmatically mediated, and thus multistable technicity of things, but rather on how the things themselves mediate the subject-object relation.

\section{The Empirical Turn}

As mentioned many times before, postphenomenology places much emphasis on the empirical character of its approach. Yet, it does not bother with defining the empirical; hence the exact meaning of its "empirical turn" remains rather unclear.

Quite clear however is, in fact, the negative or polemical meaning of the empirical insofar as postphenomenologists claim allegiance to what Hans Achterhuis (2001) dubbed the empirical turn in the philosophy of technology. In the "Introduction" to the influential book American Philosophy of Technology: The Empirical Turn which he edited, Achterhuis distinguishes the "classical philosophy of technology" (represented by thinkers like Heidegger, Jonas, or Ellul) concerned "more with the historical and transcendental conditions that made modern technology possible than with the real changes accompanying the development of a technological culture" (Achterhuis 2002: 3) from a new kind of philosophy of technology, practised by the thinkers represented in his book (Borgmann, Dreyfus, Feenberg, Haraway, Ihde, Winner) whose main concern are those "real changes". There is no reason to analyse Achterhuis' definition of the empirical in detail (especially because his list includes quite diverse and mostly non-postphenomenological thinkers). What we should take notice of is the general gesture against the "classical philosophy of technology" for its being too abstract, losing contact with real technologies, and being unable to see "the co-evolution of technology and society" (see Achterhuis 2002: 6). Verbeek's criticism of Lemmens mentioned above (Verbeek 2017) echoes this gesture: we need an "empirically informed" approach based on investigating "actual technologies," and not the "traditional" approach applying "pre-given" and too abstract 
philosophical frameworks "from outside". Or, to put it with Secomandi, "from a philosophical perspective, to be empirical, among other things, means distancing oneself from sweeping analyses at high abstraction levels, in order to focus on the particularities of concrete practices of technology design and use" (Secomandi 2018: 83).

I leave aside the question of whether Achterhuis' account of the "classical" philosophy of technology is adequate. In any case, his description is useful insofar as it demarcates what postphenomenology does not want to do. Seeking to identify what it wants to do instead, and how it intends to proceed empirically, we can see that, by an empirically "based" or "informed" or "driven" approach, it has usually meant a method based on studying concrete human relations with concrete technologies, i.e., a case-studies approach (see, e.g., Rosenberger and Verbeek 2015: 32). Simply put, the postphenomenological approach is empirical insofar as it deals, and stays in touch, with empirically given technologies, and not with abstract concepts or (transcendental) conditions. And, when staying in touch with the technologies, it seeks "to investigate the character of the various dimensions of the relations between humans and these technologies, and their impact on human practices and experiences" (Rosenberger and Verbeek 2015: 31). As one can see, after choosing a technology she will turn to, a postphenomenologist has a lot to do: she must identify all the relations this technology enters (and can enter) into so as to reveal all the effects of these relations on human experiencing. I explicitly point out these different dimensions to be able to formulate more concretely the question regarding the empirical character of the postphenomenological approach: For not only the technological objects can be identified empirically, but also the relations "arising around" them and the effects of these relations can be analyzed in an empirical way.

According to Rosenberger and Verbeek, "an empirical account ... of the role actual technologies play in human experiences and practices ... can be developed on the basis of empirical work by others, from self-conducted studies, or from an analysis of first-person experiences that involve specific technologies" (Rosenberger and Verbeek 2015: 31). Yet the editors of Postphenomenological Methodologies express their discontent with postphenomenologists who "base their analyses on texts from science journals and magazines or from their own personal life stories" (Aagaard et al. 2018: xvii). As a remedy to "postphenomenology's reliance on autoethnographical examples," they suggest "using the empirical methods of social science" to do justice especially to "social and cultural aspects of human experience" (Aagaard et al. 2018: xvii). I mention this (self-)criticism as it points to a crucial problem: in what way can we, or even must we, use other than phenomenological methods when seeking to elucidate experience? The editors' concern can be reformulated thus: personal experiences, though necessary, do not provide case studies yet. And to develop an account of those experiences, or to transform cases into case studies, we need social sciences: we need science to understand experience. Implicit here is the conviction that phenomenology itself is not up to the task. From the phenomenological perspective, however, the turn to the scientific empirical methods remains questionable. Phenomenology turns to experience to be faithful to the world as it is given in phenomena and to prevent bringing preconceived interpretations into it. But, the sciences are (called) empirical not because they deliver phenomena. 
Each empirical science is theoretically laden insofar as it develops specific methods to attain its empirical data. Hence, postphenomenology as a phenomenological approach cannot take the findings of the empirical sciences as if they were identical to phenomena: we leave here the "area" of the empirical in the sense of an immediate experience with particular technologies.

I do not claim that it is impossible to connect (post)phenomenology with empirical sciences. What I do claim is that such a connection is not a matter of course but must be supplied with sound theoretical grounding. But, instead of proclaiming that postphenomenology "is not empirical enough" (Aagaard et al. 2018: xvii), I would say that it is not phenomenological enough, and hence not empirical enough (yet in a different sense than meant by the editors). When building on "cases," postphenomenology focuses on studying what could be called "use(r) cases". Working on the assumption that technology is that which is used/seen as technology, it takes for granted our natural perspective, or the perspective of the users of technology. Postphenomenology seems to presuppose, quite understandably indeed, that it must focus on technologies that are used, and insofar as they are used, since they influence intentionality exactly by being used. But such an approach does not capture all that should be analyzed and elucidated by (post)phenomenology. Asle H. Kiran rightly underlines that technologies "harbour several virtual actions, many of which are surprising side effects to what they were designed to do" (Kiran 2012: 79). In a standard postphenomenological view, this harbouring would indicate a technology's multistability: the thing can gain many functions depending on what we do with it. What I seek to emphasize, instead, is that the thing can mediate our action not as (or when) being used differently but exactly as a side effect to its function in use. Technologies influence intentionality and the humanworld relation not only by the very functions they realize as pragmatically conceived and pragmatically used technologies. For example, a car does not change intentionality merely as a means of transport. It influences intentionality in other ways as well, while these effects are, from the perspective of the function of a car, unintended and unintentional. Any philosophy of technology must include these (side)effects, and hence also their causes, into its research field. I suggest that postphenomenology as an empirically oriented approach should seek to identify these empirical causes or sources.

Allow me to recall the discussion between Verbeek and Lemmens mentioned above. According to Verbeek, philosophy of technology "is in need of realism" (Verbeek 2017: 304): researchers must stay in touch with empirically given technologies. Lemmens objects that Verbeek's approach is in fact not "realistic" in the phenomenological sense. The question remains: How to be realistic about technologies in their influencing experience? Based on the aforesaid, I suggest that postphenomenology, in its empirical character, should conceive of its research field more broadly: instead of limiting its focus on that which "naturally" appears as technology, it must seek to reveal what is not seen as technology but still influences the human-world relation. Let me formulate it as a hypothesis: intentionality might be most constitutively influenced by the things in technology that we do not see as technology. But going even further: postphenomenology should seek to identify the things or elements that we do not see as technology at all. It remains a task for another paper to describe such an approach in more detail. 


\section{Conclusion: Searching for Things Themselves}

To begin summarizing the results of my critical reflection, let me quote a precise definition of the postphenomenological method by Jochem Zwier, Vincent Blok, and Pieter Lemmens: postphenomenology is an "empirical inquiry into the structural ways in which particular technologies mediate experiential correlations and associated subject-object constitutions that appear in specific contexts of technology use" (Zwier et al. 2016: 317). I cite this definition also because its authors develop a criticism of postphenomenology which partially overlaps with mine. Nevertheless, where I have deliberately abstained from posing the question of ontology, and ontological questions, they criticize postphenomenology by demonstrating its being, unwittingly, technically mediated in an ontological way (Zwier et al. 2016: 313). I am in concord with their criticism especially regarding the pragmatic horizon of postphenomenology. I hope to enrich and complement their argumentation by offering an analysis which is less ontological, as the ontological questioning can quite easily be dismissed, from the perspective of current postphenomenology, as too abstract and speculative. I have chosen this "strategy" also because postphenomenologists, although occasionally acknowledging criticisms of their approach (see esp. Rosenberger 2017), do not seem particularly interested in defending their position against their ontologically oriented critics. Now, just like Robert C. Scharff, another diligent critic of postphenomenology (see, e.g., Scharff 2006 and 2012), I agree with Eugene T. Gendlin (2017) that "whatever might happen among other philosophers, phenomenologists, as a matter of principle, cannot really 'disagree", (Scharff 2020: 76). Phenomenology is not so much about arguing but rather about making visible or, to put it in a bit of a subjectivist way, sharing one's own experience with phenomena. Accordingly, I have tried to point out what I find problematic in how postphenomenology conceptualizes its "thing".

I have sought to demonstrate that to fully realize the impact of technology on experience, we must not take for granted what the technicity of a thing is. In particular, we must not reduce it to its functioning in pragmatical human contexts. I claim neither that technicity as it should be analyzed by (post)phenomenology is an intrinsic property of the thing, nor that it is autonomous in the sense of being completely independent of human relation to it. What I do claim is that technologies influence experience also otherwise than as useful and used components of our lifeworld. Hence, postphenomenology should pay attention not only to the utility value, and function, of technologies but to the pragmatically "invisible" parts of them. Risking an oversimplification, I would tentatively call this dimension their materiality - understood as the opposite to their (pragmatic) functionality. By naming this dimension "material," I do not intend to deprive it of its own abilities; yet they are different from what technologies do, and can do, as parts of human pragmatic horizons. Methodologically, then, without denying that technologies can only be understood in the human relations in which they are involved, postphenomenology should not aim at revealing all the possible pragmatic relations which technologies can enter but rather on how the real inclusion of technologies into our lives unpredictably influences "human" intentionality, i.e., our being in the world. 
This dimension is accessible without questioning what some interpreters would call an "artifactual turn" (see, e.g., Coeckelbergh 2021): Postphenomenology can still focus, empirically, on particular technologies while searching for that in them which is irreducible to their pragmatic functions but still influences intentionality. However, although the artifactual turn may seem fully in accord with the demand of going back to things themselves, the matter is much more complicated. First, if (post)phenomenology wants to go back to the things themselves, one may wonder why limit the focus on technological artifacts only; principally, it should focus on all artifacts, and even on all things insofar as they shape experience. Second, even if we accept the (limited) focus on technology, postphenomenology must reflect on the following question: how do we realize that something is technology in the first place? More specifically, is it self-evident that we can, or even should, limit technology to particular artifacts? This defence mechanism against falling into the trap of merely speculating about technology is in danger of throwing the baby out with the bathwater. Insofar as postphenomenology aims at clarifying the process of technological, and not merely artifactual, mediation, it cannot but apply some idea of what technology is - and it should formulate this idea explicitly, i.e., conceptualize it, rather than working with seemingly intuitive understanding of it (to repeat the negative part of my argumentation, technology cannot be reduced to what we use or see as technology). Let me be clear: I do not claim that there is one eternal essence of technology. What I do claim is that we cannot do without seeking to explicitly define what technology currently is to be able to clarify, as postphenomenology aspires, the essential empirical causes, to put it a bit paradoxically and provocatively, of technological mediation. As indicated above, this would allow us to reveal the process of technological mediation even there where we do not naturally see the things or elements as technology. It is perhaps here where the things themselves to be analyzed by postphenomenology lie.

Open Access This article is licensed under a Creative Commons Attribution 4.0 International License, which permits use, sharing, adaptation, distribution and reproduction in any medium or format, as long as you give appropriate credit to the original author(s) and the source, provide a link to the Creative Commons licence, and indicate if changes were made. The images or other third party material in this article are included in the article's Creative Commons licence, unless indicated otherwise in a credit line to the material. If material is not included in the article's Creative Commons licence and your intended use is not permitted by statutory regulation or exceeds the permitted use, you will need to obtain permission directly from the copyright holder. To view a copy of this licence, visit http://creativecommons.org/licen ses/by/4.0/.

\section{References}

Aagaard, B. F., Sorensen, T., \& Hasse, (Eds.). (2018). Postphenomenological methodologies: New ways in mediating techno-human relations. Lexington Books.

Achterhuis, H. (Ed.). (2001). American philosophy of technology: The empirical turn (trans: Crease, R.P.). Indiana University Press.

Coeckelbergh, M. (2021). Earth, technology, language: A contribution to holistic and transcendental revisions after the artifactual turn. Foundations of Science. https://doi.org/10.1007/s10699-020-09730-9 
Gendlin, E. T. (2017). Two phenomenologists do not disagree. In E. T. Gendlin (Ed.), Saying what we mean: Implicit precision and the responsive order (pp. 5-21). Northwestern University Press.

Harman, G. (2002). Tool-being: Heidegger and the metaphysics of objects. Open Court.

Harman, G. (2017). Object- oriented ontology: A new theory of everything. Penguin Books.

Heidegger, M. (1977). The question concerning technology and other essays (trans: Lovitt, W.). Harper and Row.

Husserl, E. (1970). Logical investigations (trans. J.N. Findlay). Humanities Press.

Ihde, D. (1990). Technology and the lifeworld: From garden to earth. Indiana University Press.

Ihde, D. (1993). Postphenomenology: Essays in the postmodern context. Northwestern University Press.

Ihde, D. (2009). Postphenomenology and technoscience: The Peking University lectures. SUNY Press.

Ihde, D. (2012). Experimental phenomenology. Multistabilities. SUNY Press.

Kiran, A. H. (2012). Technological presence: Actuality and potentiality in subject constitution. Human Studies, 35(3), 77-93.

Lemmens, P. (2017). Love and realism. Foundations of Science, 22, 305-310.

Rosenberger, R. (2014). Multistability and the agency of mundane artifacts: From speed bumps to subway benches. Human Studies, 37(3), 369-392.

Rosenberger, R. (2017). Notes on a nonfoundational phenomenology of technology. Foundations of Science. https://doi.org/10.1007/s10699-015-9480-5

Rosenberger, R., \& Verbeek, P. P. (Eds.). (2015). Postphenomenological investigations: Essays on human-technology relations. Lexington Books.

Scharf, R. C. (2020). Postphenomenology, a technology with a shelf-life? Ihde's move from Husserl toward Dewey. In G. Miller \& A. Shew (Eds.), Reimagining philosophy and technology, reinventing Ihde (pp. 63-86). Springer.

Scharff, R. C. (2006). Ihde's albatross: Sticking to a 'phenomenology' of technoscientific experience. In E. Selinger (Ed.), Postphenomenology: A critical companion to Ihde (pp. 131-144). SUNY Press.

Scharff, R. C. (2012). Empirical technoscience studies in a comptean world: Too much concreteness? Philosophy and Technology, 25, 153-177.

Secomandi, F. (2018). Service interfaces in human-technology relations a case study of self-tracking technologies. In B. F. Aagaard \& T. H. Sorensen (Eds.), Postphenomenological methodologies new ways in mediating techno-human relations (pp. 83-102). Lexington Books.

Verbeek, P. P. (2005). What things do: Philosophical reflections on technology, agency, and design (trans: Crease, R.P.). Penn State University Press.

Verbeek, P. P. (2008). Cyborg intentionality: Rethinking the phenomenology of human-technology relations. Phenomenology and the Cognitive Sciences, 7(3), 387-395.

Verbeek, P. P. (2011). Moralizing technology: Understanding and designing the morality of things. University of Chicago Press.

Verbeek, P. P. (2016). Toward a theory of technological mediation a program for postphenomenological research. In J. K. B. O. Friis \& R. C. Crease (Eds.), Technoscience and postphenomenology the manhattan papers (pp. 189-204). Lexington Books.

Verbeek, P. P. (2017). The struggle for technology: Towards a realistic political theory of technology. Foundations of Science, 22, 301-304.

Zwier, J., Blok, V., \& Lemmens, P. (2016). Phenomenology and the empirical turn: A phenomenological analysis of postphenomenology. Philosophy and Technology, 29, 313-333.

Publisher's Note Springer Nature remains neutral with regard to jurisdictional claims in published maps and institutional affiliations. 